\title{
Urban Green Spaces and an Integrative Approach to Sustainable Environment
}

\author{
Shah Md. Atiqul Haq \\ Department of Asian and International Studies, City University of Hong Kong, Hong Kong, China \\ Email: shahatiq1@yahoo.com \\ Received January $5^{\text {th }}, 2011$; revised March 26 ${ }^{\text {th }}, 2011$; accepted May $3^{\text {rd }}, 2011$.
}

\begin{abstract}
This paper explains the benefits and challenges of urban green spaces based on the critical discussion of study results from different studies in different cities. The important roles played by green spaces are social, economic, cultural and environmental aspects of sustainable development. Urban green spaces can be a comprehensive tool for long term protection of environmental sustainability through improving the quality of life and air quality, increasing property value due to their amenity and aesthetic characteristics, and reducing the energy costs of cooling buildings. Urban green spaces also can provide ecosystem services in which the recreation and relaxation facilities are especially available to urban dwellers and tourists too. To confirm the multiple roles played by green spaces, certain level of qualitative improvements and distribution of green spaces within the urban area should be considered and incorporated effectively into the environmental sustainability agenda. To do this, an integrated approach regarding the planning, monitoring, designing and maintaining of urban green spaces is required for improving the environmental sustainability in cities in different countries.
\end{abstract}

Keywords: Integrative Approach, Socio-Economic Value, Sustainable Environment, Urban Green Spaces

\section{Introduction}

Urban green spaces as an important contributor can be a significant part of sustainable development. Developments of urban green spaces need to consider interdisciplinary and integrative approaches such as economic, political, social, cultural, management and planning aspects to improve existing urban green spaces' facilities and services, and to optimize urban green space policies [1]. The definition of urban green spaces which is agreed on by ecologists, economists, social scientists and planners is public and private open spaces in urban areas, primarily covered by vegetation, which are directly (e.g. active or passive recreation) or indirectly (e.g. positive influence on the urban environment) available for the users [2]. Based on the studies of different cities, different researchers provide some guidelines to evaluate the nature of green spaces. Firstly, one of the main factors in determining the nature of green spaces is their quantity in the city [3]. Secondly, existing qualities like activities and experiences, and perceived benefits to the users determine the utilization of green spaces [4]. Thirdly, the functionality of those green spaces is equally influenced by the location and distribution (accessibility) in the whole city [4-6].

Irrespective of level of development of any country, many countries are facing one of the most important challenges: the adequate development of sustainable cities. In this regard, urban green spaces can provide social, economic, cultural and psychological services especially for the wellbeing of the urban dwellers and for tourists as well. Sustainable development of cities and development of urban green spaces are very important, since almost half of the world population now live in urban area where the pace for rural-urban migration and pressure from international migration in developed countries is still high, as most of the immigrants in developed countries live in central or big cities of the country. Moreover, it is an urgent need to improve the lifestyles of urban people and there should be a special focus on the consideration of environmental impact of human activities by raising awareness to the rational use of energy, water and food consumption and natural resources for environmental sustainability. Finally, the role played by green spaces in our urban environments can no longer be ignored by today's policy makers.

Since many studies conducted in cities in Europe, Asia and USA show the enormous challenges in providing 
quality level green spaces and adequate green spaces in the cities. To get maximum level contribution from urban green spaces, local approach and integrative approaches should be focused to overcome the challenges faced by different cities in different countries including the land allocation, size and number of green spaces based on the number of urban dwellers, accessible facilities for dwellers or tourists. Finally, the paper is based on the relevant studies and literature reviews to explain the benefits of green spaces, functionality of urban green spaces. And how and what ways the application of integrative approach can contribute to a potential solution to environmental sustainability in different cities, especially in developing countries in consider to the challenges usually coming from socio-economic factors, culture, population growth, inadequate management, lack of proper implementation of environmental policies, excessive unplanned rural-urban migration.

\section{Benefits of Urban Green Spaces}

\subsection{Environmental Benefits}

\subsubsection{Ecological Benefits}

Urban green spaces supply to cities with ecosystem services ranging from maintenance of biodiversity to the regulation of urban climate. Comparing with rural areas, differences in solar input, rainfall pattern and temperature are usual in urban areas. Solar radiation, air temperature, wind speed and relative humidity vary significantly due to the built environment in cities [7]. Urban heat island effect is caused by the large areas of heat absorbing surfaces, in combination of high energy use in cities. Urban heat island effect can increase urban temperatures by $5^{\circ} \mathrm{C}$ [8]. Therefore, adequate forest plantation, vegetation around urban dweller's house, management of water bodies by authorities can help to mitigate the situation.

\subsubsection{Pollution Control}

Pollution in cities as a form of pollutants includes chemicals, particulate matter and biological materials, which occur in the form of solid particles, liquid droplets or gases. Air and noise pollution is common phenomenon in urban areas. The presence of many motor vehicles in urban areas produces noise and air pollutants such as carbon dioxide and carbon monoxide. Emissions from factories such as sulphur dioxide and nitrogen oxides are very toxic to both human beings and environment. The most affected by such detrimental contaminants are children, the elderly and people with respiratory problems [9]. Urban greening can reduce air pollutants directly when dust and smoke particles are trapped by vegetation. Research has shown that in average, $85 \%$ of air pollution in a park can be filtered [8].
Noise pollution from traffic and other sources can be stressful and creates health problems for people in urban areas. The overall costs of noise have been estimated to be in the range of $0.2 \%-2 \%$ of European Union gross domestic product [8]. Urban green spaces in over crowded cities can largely reduce the levels of noise depending on their quantity, quality and the distance from the source of noise pollution. In the contemporary studies on urban green spaces consider the complex urban ecosystem, conservation of the urban green spaces to maintain natural ecological network for environmental sustainability in cities. For the cities in fast urbanizing and growing economy, country like China should consider the dynamic form of urban expanding to manage effective urban green spaces which will contribute to reduce the overall $\mathrm{CO}_{2}$ by maintaining or even increasing the ability of $\mathrm{CO}_{2}$ absorption via natural eco-system [10]

\subsubsection{Biodiversity and Nature Conservation}

Green spaces do functions as protection centre for reproduction of species and conservation of plants, soil and water quality. Urban green spaces provide the linkage of the urban and rural areas. They provide visual relief, seasonal change and link with natural world [11]. A functional network of green spaces is important for the maintenance of ecological aspects of sustainable urban landscape, with greenways and use of plant species adapted to the local condition with low maintenance cost, self sufficient and sustainable [12].

\subsection{Economic and Aesthetic Benefits}

\subsubsection{Energy Savings}

Using vegetation to reduce the energy costs of cooling buildings has been increasingly recognised as a cost effective reason for increasing green space and tree planting in temperate climate cities [7]. Plants improve air circulation, provide shade and they evapotranspire. This provides a cooling effect and help to lower air temperatures. A park of $1.2 \mathrm{~km}$ by $1.0 \mathrm{~km}$ can produce an air temperature between the park and the surrounding city that is detectable up to $4 \mathrm{~km}$ away [7]. A study in Chicago has shown that increasing tree cover in the city by $10 \%$ may reduce the total energy for heating and cooling by 5 to $10 \%$ [9].

\subsubsection{Property Value}

Areas of the city with enough greenery are aesthetically pleasing and attractive to both residents and investors. The beautification of Singapore and Kuala Lumpur, Malaysia, was one of the factors that attracted significant foreign investments that assisted rapid economic growth [9]. Still, indicators are very strong that green spaces and landscaping increase property values and financial returns for land developers, of between $5 \%$ and $15 \%$ de- 
pending on the type of project [7].

\subsection{Social and Psychological Benefits}

\subsubsection{Recreation and Wellbeing}

People satisfy most of their recreational needs within the locality where they live. Findings by Nicol and Blake (2000) show that over $80 \%$ of the UK's population live in urban areas, and thus green spaces within urban areas provide a sustainable proportion of the total outdoor leisure opportunities. A study conducted in Helsinki, Finland, indicated that nearly all (97\%) city residents participate in some outdoor recreation during the year. Half of the residents make outdoor visits on a daily basis or every second day [6]. Urban green spaces serve as a near resource for relaxation; provide emotional warmth [7]. In Mexico City, the centrally located Chapultepec Park draws up to three million visitors a week who enjoy a wide variety of activities [9].

\subsubsection{Human Health}

People who were exposed to natural environment, the level of stress decreased rapidly as compared to people who were exposed to urban environment, their stress level remained high [8]. In the same review, patients in an hospital whose rooms were facing a park had a $10 \%$ faster recovery and needed 50\% less strong pain relieving medication as compared to patients whose rooms were facing a building wall. This is a clear indication that urban green spaces can increase the physical and psychological wellbeing of urban citizens. In another research conducted in Swedish cities showed that the more time people spend outdoors in urban green spaces, the less they are affected by stress [5]. Certainly, improvements in air quality due to vegetation have a positive impact on physical health with such obvious benefits as decrease in respiratory illnesses. The connection between people and nature is important for everyday enjoyment, work productivity and general mental health [9].

\section{Challenges toward Management of Urban Green Spaces}

\subsection{Socio-Economic and Demographic Factors}

High urbanization and the high pace of social and economic development in Asia resulting from the increase of population in cities, lack of infrastructure, congested traffic, environmental degradation and a housing shortage are major issues faced by cities in Asia in their sustainable development [13]. According to population experts, 62 percent of the world' population will live in urban areas by the year 2020, while the Asia-Pacific Region will contain about 49 per cent of that urban population and will have contained a level of urbanization of 55 per cent [13]. But it is also need to mention that growth of population has been slowed down in Asia-Pacific region.
The great threat to health and safety in cities comes from water and air pollution. Especially those who are poor and do not have adequate ventilation systems, air pollution is hazardous for them women and children because they expose regularly and waterborne diseases are found most commonly in low-income groups because of inadequate sanitation, drainage and solid waste collection services [13]. Another most important challenge facing in Asia region due to over urbanization is the conversion of agricultural land and forest for urban uses and the development of infrastructure in urban areas. As a result, widespread removal of vegetation to support urban ecosystem, ground water overdraft and put additional pressure on nearby areas may be even more ecologically sensitive and may even increase the higher frequency of flooding in urban areas [13].

Cities cover $2 \%$ of land space worldwide but consume $75 \%$ of the resources [14]. Exposing city dwellers to local biodiversity can also trigger interest in environmental issues, especially since people's first encounter with the environment is often in one's home city or town rather than in distant places [14]. The lack of established and zoned green space is a factor of urban sprawl as people move to the edge of a city to be closer to the rural setting that feels like a healthier environment [14]. To meet socio-economic, environmental, psychological needs of urban dwellers, there should develop some criterion based on the attitudes of perceived user to shape adequate uses of land and provide facilities within urban green spaces in cities [15]. Planning authorities were advised to adopt a strategic approach and plan positively for providing green spaces. This was to provide strong protection for existing ones, resist new development opportunities which might diminish recreational provision, ensure accessibility, and to provide good quality green spaces and recreational facilities [16]

\subsection{Quantitative Aspects of Urban Green Spaces}

Understanding relationship between the urban population and the amount of green spaces is particularly important in evaluating their functionality, and of course future planning for their provision. Commonly used terms to refer to the quantity of green spaces are green space ratio, green space coverage and green space area per capita [17]. It is very difficult to measure the appropriate amount of required land and allocation of land and calculate distance from residential area and especially to implement the measurement on building up urban green spaces with proper services in the highly populated countries. Table 1 shows the standards of minimum sizes of various types of green spaces in urban areas [4].

A study on 26 cities from 15 European countries considers four groups of the 26 cities, according to their 
population size, such as Metropolis, Big Cities, Medium-Sized Cities and Small Cities [2]. To understand the availability of urban green spaces in Europe, the study conducts factor analysis by considering the factors"mixed land use" (such as residential areas, industrial areas, forest and agricultural areas); "man-made environment” (such as built-up area and urban green areas); and water [2]. And the study finds that metropolis has a high score on man-made environment which includes built-up area and urban green [2]. Considering the four groups of variables such as urban green areas, forests, agricultural areas and water, another factor analysis shows the two categories of cities included in the study"Natural Green Areas" (N) (such as forest and agricultural areas) and "Urban Green Areas" (U) ( such as urban green and water). Finally, the study concludes that the metropolis and the big cities have a high score on the urban green factor [2]. Because the cities are old, the cities have a high population density and the cities have a loss of natural areas and natural resources. In addition, medium-sized cities have a relatively high score on the natural green factor due to the availability of natural green areas [2].

However, the study suggests investing more in urban green spaces in metropolis cities and less invest in urban green spaces in medium-sized cities [2]. But it is important to preserve the green areas either urban green or natural green. To confirm the conservation and to improve the better quality of urban green spaces or natural green spaces, appropriate measurements, monitoring, planning, management based on participatory and integrative approach is very essential in cities in developed countries and most importantly in cities in developing country. Table 2 shows the availability of natural and urban green spaces.

As most cities, especially in developing world continue to grow in population there is seemingly continued decrease in urban space at the expense of built up areas. Despite the trend, studies show that people are willing to pay high prices for green spaces increment [18]. Urban

Table 1. Minimum standards for urban green spaces.

\begin{tabular}{ccc}
\hline Functional level & $\begin{array}{c}\text { Maximum diatance } \\
\text { from home }(\mathrm{m})\end{array}$ & $\begin{array}{c}\text { Minimum } \\
\text { surface (ha) }\end{array}$ \\
\hline $\begin{array}{c}\text { Residential } \\
\text { green }\end{array}$ & 150 & \\
$\begin{array}{c}\text { Neighbourhood } \\
\text { green }\end{array}$ & 400 & 1 \\
Quarter green & 800 & 10 (park: 5 ha) \\
District green & 1600 & 30 (park: 10 ha) \\
City green & 3200 & 60 \\
Urban forest & 5000 & $>200$ (smaller towns) \\
\hline
\end{tabular}

Source: Herzele and Wiedemann, 2003. park movement was created with an objective of increasing the city life quality of the industrial revolution era. The movement saw creation of massive green spaces, particularly urban parks such as central park of New York City, the Amsterdam's Bos Park, City park of porto, in developed countries [12].

Distance or walking time from home has appeared to be the single most important precondition for use of green spaces [4]. People in close proximity to a green space use it more frequently. Studies have shown that the location and distribution of green spaces in the city influences people participation. A study in Helsinki, Finland, showed that a good amount of green areas and easy access (i.e. short distance) to a recreational space increase the number of visits and people living close $(<0.5 \mathrm{~km})$ visited the green spaces more frequently $(>4$ times per week) [6]. For instance, a study in Swedish cities showed that in overall, people with immediate access to fine and verdant gardens or green yards are also more likely to visit public green spaces. Indeed, those with gardens of their own also spend more time in public green spaces than those without a garden of their own [5].

Public green space should be at the centre of neighbourhood and not more than five minutes walk for most residents, public buildings or shops [19]. Therefore, accessibility and proximity are very important factors to consider during planning and design of an urban green space. The distance one walks or cycles should be adequately short as well as with limited obstructions along the trip. As such, some countries have set up recommendations for the provision of accessible green spaces. For instance, Britain has standards such as an accessible natural green space less than 300 metres from homes; statutory local nature reserves provided at a minimum level of 1 hectare per thousand populations, at least one accessible 20 hectare site within 2 kilometres of home; one accessible 100 hectare site within 5 kilometres of home and one accessible 500 hectare site within 10 kilometres of home [20].

\subsection{Qualitative Aspects of Urban Green Spaces}

The evaluation of recreational green spaces has to be centred on the variety of qualities available, sufficiently satisfying and interesting place to encourage people to stay and enjoy being there [4]. A study conducted in western Colorado showed that people enjoy varied physical and social opportunities in green spaces. The benefits people desire can directly be linked to a particular recreational activity and to physical, social and management setting characteristics. Most people cited getting away from daily demands of life and relieving stress as the reason for visiting green spaces [21]. 
Table 2. Availability of natural and urban green in European cities.

\begin{tabular}{|c|c|c|c|c|}
\hline $\begin{array}{l}\text { Metropoles Population: } \\
1.000 .000+\end{array}$ & $\begin{array}{l}\text { Big Cities Population: } \\
500.000-1.000 .000\end{array}$ & \multicolumn{2}{|c|}{$\begin{array}{l}\text { Medium-Sized Cities Population: } \\
100.000-500.000\end{array}$} & $\begin{array}{c}\text { Small Cities } \\
\text { Population: } 100.000\end{array}$ \\
\hline Berlin (U) & Birmingham (U) & Antwerp & Leipzig (N) & Alphen aan de Rijn \\
\hline Budapest (U) & Cracovia (N) & Bern & Montpellier & Freiberg \\
\hline Istanbul (N) & Genoa & Chemnitz (N) & Salzburg & Gorlitz \\
\hline Vienna (U) & Helsinki (U) & Dresden (N) & Sarajevo & \\
\hline \multirow[t]{2}{*}{ Warsaw (U) } & Lodz (N) & Edinburgh (U) & Tallinn & \\
\hline & Turin & Espoo (U) & Zurich & \\
\hline
\end{tabular}

U: Urban Green N: Natural Green; Source: Tuzin and others, 2002.

Planning urban green spaces requires the designer's views and the users' views integration. For instance, a study in Madina town showed that the highest number of users (71\%) wants grass/ turf and the highest number of users $(84 \%)$ wants evergreen plants in their green spaces [22]. That indicates that during the planning and management process, a consideration of users' perception should be considered. If the urban green spaces development strategies fail to include stakeholders' participation, which will be the reflection of the neglect of social and environmental functions [15]. A study in Ankara city, Turkey shows that the green space users' preference are such as sitting on bench, walking and running facilities, pleasant landscape, visual elements, nearness to water and peaceful atmosphere [3]. In the pursuit of creating a quality green space, the standards should be set locally, to accommodate activities and future changes. Public participation in the planning and design process is very important to incorporate their values and pattern of life in the process [3].

\section{Urban Green Spaces and Integrative Approach}

\subsection{Integrative Approach}

There is still debate regarding the approaches which will be best fitted to analyze and explain problems like social, economic, and environmental so on. However, in recent times, studies try to incorporate integrative approach to figure out complexities, underlying mechanism, and provide comprehensive and effective better solutions with newly raised issues such as environmental sustainability, climate change adaptation, environmental conservation and importance of urban green spaces especially in developing countries. Before going to relate the use of integrative approach in the challenges of urban green spaces, the meaning of integrative approach is needed to define.

Integrative studies as projects that are either interdisciplinary or transdisciplinary, in that new knowledge and theory emerges from the integration of disciplinary knowledge. With the expression of integrative research we summarize interdisciplinary and transdisciplinary research efforts [23].

In integrative research, academic participants such as researchers and nonacademic participants like societal actors-policy makers, representatives of administration or interest groups, locals or the broader public are involved [23] which is shown in Figure 1, two types of actors-researchers and non- academic participants—can cooperate in different ways in integrative research. First, researchers from one discipline cooperate with researchers from other disciplines, which can be multidisciplinary or interdisciplinary, depending on whether integration is aimed at or not. Second, researchers from one discipline can cooperate with societal actors, which can be participatory. Also here, integration is not the aim but exchange. Third, research- ers from several disciplines can cooperate with societal actors, which can be either participatory or transdisciplinary, again depending on whether the project aims at integration of knowledge or exchange [23].

Briefly, we can say that different kinds of knowledge come together to answering a research question using different kinds of approaches. Though, social sciences, humanities, physical sciences and medical sciences use their own approaches to produce knowledge and analyze data, and there still exists a debate between qualitative vs. quantitative analysis for data validation and exploitation.

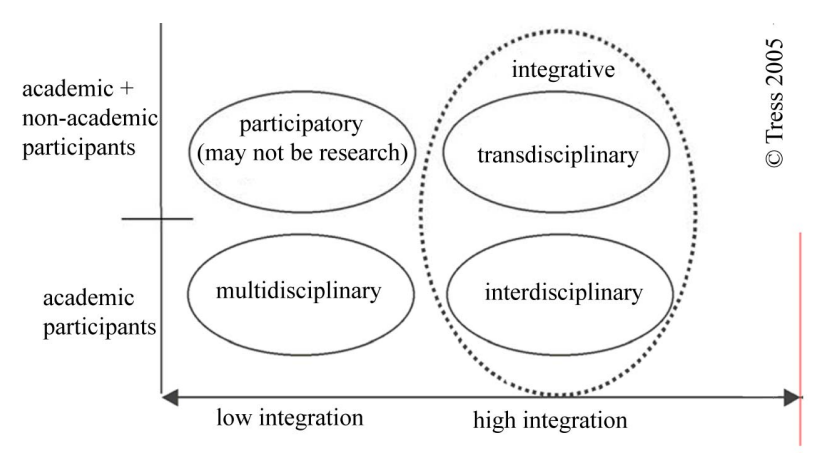

Figure 1. Level of Integration. Source: Tress, Tress and Fry, 2005. 
But in integrative research, the research questions or problems will be derived and articulated jointly where stakeholders will participate and have an endeavour to answer research questions from different disciplinary approaches without depending on a single or particular aspect. And there will be a high integration using the transdisciplinary and interdisciplinary approaches to find solution of a problem like challenges of urban green spaces, climate change, and environmental sustainability.

\subsection{Integrative Approach and Environmental Sustainability}

The quality of cities depends on how the urban green spaces are designed, managed and protected. The management, planning, design, policy implementation of urban green spaces as the key discussion issues of sustainable environment are highly integrated and incorporated into the sustainable development at local and global level [2]. Urban green spaces not only play role to environment but also it contributes to social, economic, recreation, cultural, visual aspects and commercial developments in cities.

The social aspects of urban green spaces include diversity of land uses, contribution to health and active life styles in cities, social justice by incorporating all groups and ages of people into green spaces, opportunities to interact and expand social network [24], enhancement of cultural life for different communities living in the city by providing a platform to share views, feelings and to celebrate different groups occasions and, a venue for environmental education for the schoolchildren [2] and a play ground for children [25] for the social, mental and physical development. From the planning aspects, urban green spaces include business, retail, leisure development, tourism development; employment centers besides residential areas [24] and the good planning of urban green spaces can play a role as a visual screen, a function of noise protection and a place for commuting and recreation by providing well-designed networks within the park and with the other areas [26]. The economic aspects of urban green spaces incorporate- as a place for production and supply of fruits, wood to green business centers, and as a place for new jobs creation and increasing economic value of the area by integrating the environment friendly behavior and attracting tourists provided with convenient atmosphere, security and facilities for the tourists [2]. Most importantly the ecological perspective considers urban green spaces as a facilitator to reduce the impact of human activities through absorbing pollutants and releasing oxygen [27]; contributing to the maintenance of a healthy urban environment with clean air, water and soil [27] and preserving the local natural and cultural heritage with a diversity of urban wildlife and urban resources

\section{[2].}

In the pursuit to establish environmental sustainability and sustainable management of urban green spaces, the local authorities should maintain a database of actual and potential green spaces graded according to landscape and ecological values. This would help in developing a management plan [28]. A conservation plan should be prepared to protect the urban green spaces enclaves from intrusion by other land uses and to ensure that the natural ingredients of flora, fauna, landforms, soil and water continue to flourish. Urban green spaces management plans should be in place early before the inception of the design process. When considering the cost of developing a green space, one should keep in mind this direct relationship; if you build it, you must maintain it [29].

\section{Conclusions}

Urban green spaces fulfil many functions in urban context that benefits people's quality of life. There is therefore a broad consensus about the importance and value of urban green spaces in cities towards planning and constructing sustainable or eco-cities of $21^{\text {st }}$ century. Steadily growing traffic and urban heat, especially in the developing countries is not only damaging the environment but also incur social and economic costs. The ecological benefits bestowed in green spaces which range from protecting and maintaining the biodiversity to helping in the mitigation of change cannot be overlooked in today's sustainable planning. Inner-city green spaces are especially important for improving air quality though uptake of pollutant gases and particulates which are responsible for respiratory infections. Green spaces also help in reduction of the energy costs of cooling buildings effectively. Furthermore, due to their amenity and aesthetic, green spaces increase property value. However, the most sought benefits of green spaces in a city are the social and psychological benefits. Urban green spaces, especially public parks and gardens provide resources for relaxation and recreation. Ideally this helps in emotional healing (therapeutic) and physical relaxation.

In order to meet social and psychological needs of citizens satisfactorily, green spaces in the city should be easily accessible and in adequately optimal in quality and quantity. Green spaces need to be uniformly distributed throughout the city area, and the total area occupied by green spaces in the city should be large enough to accommodate the city population needs. Cities are responsible for most of the consumption of the world's resources and are home to most of the world's citizens as well. Bringing green space to the urban landscape can promote and inspire a better relationship with the environment while supporting important services. Green space is part of and also represents habitats and ecosys- 
tems. The promotion and conservation of green space in cities is in the hands of local and regional authorities.

Integrative approach should not be discussed only in writings as a source of contributing instrument to environmental sustainability, but it is also important that how it could be fostered in developing countries in different social settings in which deffrent economic, political and cultural factors influence. And there are many intermediary factors such as lack of investment, proper management, designing an appropriate planning and puplic policy, and political instability, social values, economic circumstances influence to how and what extent the application of integrative approach in developing countries can contribute to environmental sustainability. Scientific and technological development of a country is both dependent on social context and political [30]. In this regard, integrative research with incorporation of participation from different level stakeholders i.e. academic and non-academic is essential to foster sustainable development in the context of challenges toward urban green spaces.

\section{REFERENCES}

[1] URGE, 2002. http://www.urge-project.org

[2] B. Tuzin, E. Leeuwen, C. Rodenburg and N. Peter, Paper presented at the 38th International Planning Congress on "The Pulsar Effect” Planning with Peaks, Glifada, Athens, 21-26 September 2002.

[3] D. Oguz, "User Survey of Ankara’s Parks,” Elsevier Science: Landscape and Urban Planning, Vol. 52, No. 2, 2000, pp. 165-171.

[4] V. Herzele and T. Wiedeman, "A Monitoring Tool for the Provision for Accessible and Attractive Green Spaces," Elsevier Sciences: Landscape and Urban Planning, Vol. 63, No. 2, 2003, pp. 109-126. doi:10.1016/S0169-2046(02)00192-5

[5] P. Grahn and U. A. Stigsdotter, "Landscape Planning and Stress," Urban Forest: Urban for Urban Green, Vol. 2 2003, pp. 001-018.

[6] M. Neuvonen, T. Sievanen, T. Susan and K. Terhi, “Access to Green Areas and the Frequency of Visits: A Case Study in Helsinki," Elsevier: Urban Forestry and Urban Greening, Vol. 6, No. 4, 2007, pp. 235-247.

[7] V. Heidt and M. Neef, "Benefits of Urban Space for Improving Urban Climate,” Ecology, Planning and Management of Urban Forests: International Perspective, 2008.

[8] P. Bolund and H. Sven, "Ecological Services in Urban Areas,” Elsevier Sciences: Ecological Economics, Vol. 29, 1999, pp. 293-301. doi:10.1016/S0921-8009(99)00013-0

[9] M. Sorensen, J. Smit, V. Barzetti and J. Williams, "Good Practices for Urban Greening,” Inter-American Development Bank, 1997.

http://www.iadb.org/sds/doc/ENV109KKeipiE.pdf.
[10] D. Huang, C. C. Lu and G. Wang, "Integrated Management of Urban Green Space: The Case in Guangzhou China,” 45th ISOCARP Congress 2009.

[11] C. Francis, "People Places; Design Guidelines for Urban Open Space," Second Edition, John Wiley and Sons, Hoboken, 1997.

[12] L. Loures, R. Santos and P. Thomas, "Urban Parks and Sustainable Development: The case study of Partimao city, Portugal," Conference on Energy, Environment, Ecosystem and Sustainable Development, Agios Nikolaos, Greece, 2007.

[13] I. Masakazu, "Urbanization, Urban Environment and Land Use: Challenges and Opportunities,” Asia-Pacific Forum for Environment and Development Expert Meeting, Guilin, 23 January 2003.

[14] http://www.countdown2010.net/2010/wp.../FS7Greenspa ce_small.PDF

[15] S. Balram and S. Dragicevic, "Attitude towards Urban Green Spaces; Integrated Questionnaire Survey and Collaborative GIS Techniques to Improve Attitude Measurement," Elsevier: Landscape and Urban Planning, Vol. 71, No. 2-4, 2005, pp. 147-162.

[16] R. Laing, D. Miller, A.-M. Davies and S. Scott, "Urban Green Spaces; The Incorporation of Environmental VALUES in a Decision Support System,” 2006. http://www.itcom.org/2006/14/

[17] W. Xion-Jun, “Analysis of Problems in Urban Green Space System Planning in China,” Journal of forestry Research, Vol. 20, No. 1, 2009, pp. 79-82.

[18] F. Altunkasa and C. Uslu, "The Effect of Urban Green Spaces in Upper Northern Urban Development Area of Adana (Turkey)," Tubitak Journal, Vol. 28, 2004, pp. 203-209.

[19] A. Etzioni, "The Essential Communitarian Reader," Rowman and Littlefield, Lanham, 1998.

[20] C. Moughtin and P. Shirley, "Urban Design: Green Dimension,” Published by Elsevier, 2005.

[21] T. Stein and M. Lee, "Managing Recreation Resources for Positive Outcomes: An Application of Benefits Based Management," Park and Recreation Administration Journal, Vol. 13, No. 3, 1995, pp. 52-70.

[22] S. Irum, M. Alamgir, M. Gul and A. Osman, "Perceptions of Community of Madina Town towards the Undeveloped Green Spaces in Madina Town,” Pakistan Journal of Applied Sciences, Vol. 2, No. 12, 2002, pp. 1099-1101.

[23] B. Tress, G. Tress and G. Fry, "Integrative Studies on Rural Landscapes: Policy Expectations and Research Practice," Landscape and Urban Planning, Vol. 70, No. 1-2, 2005, pp. 177-191. doi:10.1016/j.landurbplan.2003.10.013

[24] Scottish Executive, "Rethinking Open Space,” The Stationery Office, Kit Campbell Associates, Edinburgh, 2001.

[25] J. Jacobs, "The Death and Life of Great American Cities," In: G. Haughton and C. Hunter, Sustainable Cities, JKP, London, 1994. 
[26] J. Dole, “Greenscape 5: Green Cities, Architects' Journal,” In: G. Haughton and C. Hunterm, Sustainable Cities, JKP, London, 1994, pp. 61-69.

[27] M. Hough, "City Form and Natural Processes, London: Croom Helm,” In: G. Haughton, and C. Hunter, Sustainable Cities, JKP, London, 1994.

[28] C. Y. Jim, "Green-Space Preservation and Allocation for Sustainable Greening of Compact Cities,” Elsevier sciences: Cities, Vol. 21, No. 4. 2004, pp. 311-320.

\section{doi:10.1016/j.cities.2004.04.004}

[29] C. Flink, C. Olka and R. M. Searn, "Trails of Twenty-First Century: Planning Design and Management Manual for Multi-Use Trails,” Island Press, Washington DC, 2001.

[30] N. Thompson, "The Contribution of the Social Sciences to Knowledge Based Development," Centre for Rural Economy Discussion Paper Series No. 13, University of Newcastle, 2007. 